\title{
Probable Uses of Flint End-Scrapers ${ }^{211}$
}

The letter by Mr. Irwin W. Cox concerning "Indian spoons" brings back memories of past years. When a youth in northeast Missouri, I never found a stone scraper; but in 1901 while examining an Indian camp site on the Missouri River in Saline County, the landowner gave me some small scrapers and asked if they were not Indian spoons. Mr. Cox's reference marks the first time since then that I have heard of that term being used. At that time people generally knew little about most types of stone artifacts. Previously I had neither seen nor heard of anything like them, but after experimenting, I decided that they must be scraping or planing tools. It was a number of years afterward before I saw similar scrapers illustrated and described in some European texts on Paleolithic man.

In central west Texas, spoon-shaped flint scrapers are found in great numbers in a majority of the surface, and near surface camp sites. My collection contains several thousand specimens. From one site more than five hundred scrapers of that type were collected. While there is a general similarity in form, there are a great many subforms, differing greatly in details of size, thickness and shape, and in the flaking technique used.

It is evident that the tribal groups which occupied certain Texas sites made one type, whereas the former occupants of nearby sites made quite different types of scrapers. While all are now surface sites, there may have been a time interval between them.

There is little doubt that the latest purely stone-age occupation of Texas was the period of the greatest use of this type of scraper, and also that as one goes down in stratified deposits, few are found much below plow depth. Some are found several feet below these shallow deposits, but generally the deeply buried scraping tools do not have the rounded keel-backed spoon-shaped form. Instead, the evidence shows a steady progression through many variant forms of side scraping tools. The nearest to this type are the large square-ended or straight cutting-edged "Clear Fork Complex" scrapers which erode from the same old surfaces where true Folsom points are found.

In one surface site many small, beautifully made oval scrapers, similar to the illustrations of those found at the Lindenmeier site with Folsom points by Roberts, have been found with generalized Folsom points. Many of these scrapers have keen points opposite the cutting ends. However this small type is not the prevailing size in this region. Out of nearly 3000 spoon-shaped scrapers found near Abilene, less than 400 were of the smaller type, and these were collected from a few sites where large scrapers were not found. All of the others were of a type which usually varies from $17 / 8$ inches to $21 / 8$ inches wide at the cutting end, and from $23 / 4$ to $3 \frac{1}{4}$ inches in length. While a few

211 This article was submitted previous to the publication of Mr. Over's article on the same subject in this journal, Vol. II, No. 3, pp. 208-209. 
are considerably larger, and some smaller, most of the scrapers are rather uniformly within the above measurements. Even the small scraper type found here averages larger than the common northern type described by Mr. Cox.

It may have been possible to have used the small scrapers to remove marrow from bones, but this must have been one of the minor local uses. The arguments would not apply here since nearly all are too large for such use. Various observations have convinced me that the spoon-shaped scraper was the Indian's common pattern for a pocketknife, and was used for most of the purposes that a boy's jackknife is.

Several years ago a farm boy who was interested in my collecting asked me what scrapers were used for. My reply was that they were Indian pocketknives and probably were used to skin animals and to clean hides. The boy was then trapping small animals for furs, and later told me with enthusiasm that he had found the small flint end-scraper to be a very much more efficient tool with which to skin a fur-bearing animal than his pocketknife, and that there was no damage to the hide when it was used, whereas accidental damage somer times occurred when he used a pocketknife. He informed me that thereaftehe always carried a flint scraper in preference to a knife for that purpose.

In the Cox letter the following statement occurs: "For hide work there would be no object in having the heavy blunt edge so carefully rounded and chipped, nor the front side smooth." On the contrary, I think that no matter how tight a hide was stretched, it would stretch somewhat to scraping pressure, and that an ordinary knife of either a straight or bevelled edge would have a tendency to bite in to the hide at the ends, if not elsewhere, and damage it, whereas the thick rounded end of the end-scraper would slide over it without biting into it, while the down and inturned cutting edge would be admirably suited to clean the surface. One can grasp a scraper between the right thumb and forefinger and draw it downward across the palm of the left hand to get the idea.

If one wants to risk cutting his hand, he can get an ordinary thin-edged flint knife or a flake knife and apply equal hard pressure, thus determining which is the most efficient scraping tool. In a flint knife the point at one end, the corner at the base and the straight edge would all be liabilities in either skinning or fleshing a hide.

In 1928, I was directed to some "old Spanish Mines" situated on top of a high, dry hill a considerable distance from water. Much to my surprise, the whole hill top was strewn with keel-backed flint end-scrapers. Over a hundred were found on the first visit, and these were lying on top of grassy sod which never had been plowed. Along the brow of the hill for a half mile were a series of deep, wide pits, where prehistoric Indians had excavated limestone slabs containing a vein of red oxide of iron or rouge. These slabs had been carried to a flat space on the hilltop to remove the red paint. Evidently the paint had been scraped off in a fine red powder with flint scrapers, since as many as three or four scrapers lay close beside and around some of the slabs, and 
scattered thickly all between them. There were no hearth rings, bones, shells, hammerstones, manos and metates, or other camp site debris, and relatively few arrowheads and knife blades.

A few small slabs had been carried to the two camp sites on the creek bank situated one and two miles away, but evidently most of the paint had been scraped from the slabs on the hill where it was mined. I picked up some of the flint scrapers, lying around the slabs, and easily scraped the red paint off in a fine powder which could be applied as dry paint. In May, 1929, Dr. Walter Hough of the U. S. National Museum was taken to the site, and this was demonstrated to him. He agreed that it undoubtedly was the explanation of the number of scrapers being found at the paint mine site. He was greatly interested in my demonstration of that use of flint scrapers, and advised me to get it into print at the earliest date, since he never before had heard of that use of scrapers. This was done in Vol. 1, September, 1929, Bulletin of Texas Archeological and Paleontological Society, pp. 17-18.

Another probable use of flint scrapers was in making bows and arrows, and scraping and polishing a variety of other wooden artifacts. I have no direct evidence of this, but when a very small child in Missouri during the eighties, I watched the country boys make excellent bows and arrows of hard, supple hickory wood, for use in rabbit hunting. After roughing these down with pocketknives, they carefully scraped and polished them smooth with broken peices of thick bottle glass. The arrows were made with round wooden points hardened by scorching on the hearth.

It is probable that this technique was a survival of that acquired from Indians by some previous generation of boys, and that the use of glass, as the scraper of wood, came from the similar use of its prehistoric flint-scraper prototype.

Perhaps flint scrapers were also used to work bone and shell ornaments. Those provided with gravers opposite the cutting ends could have been used to incise wood, bone, shell, stone and pottery, and probably were also used in tattooing, as Roberts has suggested in his 1936 Lindenmeier site report.

The statement of Mr. Cox that the sites where scrapers are found are always full of bones is also true for Texas. When we consider that the cutting ends of the Texas scrapers usually are too large to have been used to extract marrow from bones, his theory of such usage requires proof. The same abundance of buffalo bones and teeth in the sites where scrapers are found might indicate that here hunters had killed more animals, and a greater need existed for both skinning and fleshing tools. A certain proportion of scrapers are equipped with thin cutting edges at the ends opposite the thick scraping and fleshing ends. These would be as suitable for cutting the hides open, as the other ends would be for peeling them off.

These must have been the little flint tools mentioned by the early Spanish explorers of this region as used by the Indians in skinning bison, although the explorers failed to describe the type of implements used, and some assume them 
to have been the usual flint knife blades. The large scrapers found in the former bison country may have been used to skin the larger animals and the small scrapers on small fur-bearing animals.

Certain experiments of mine prove that end-scrapers were not made by pressure flaking, but by percussion. A perfect pear-shaped flint scraper can be made in about a minute's time, but that is another story.

Cyrus N. Ray

Texas Archeological and Paleontological Society Abilene, Texas 